\title{
Building the Knowledge Society by Opening Access to Scholarly Information
}

The Access to scientific information can be analyzed concerning different aspects such as: copyright, costs, communication difficulties, and business models for scientific publication in Brazil and in the rest of the world.

The crisis affecting scientific journals has been vastly discussed but, many times, the real dimensions of the cost that caused this crisis are unknown. Not long ago, the autonomous consultant Dr. Nicholas Cop began his presentation about the Open World with two images: a Pontiac G6 with leather seats and the cover of a scientific journal, Applied Polymer Science. He asked the audience: Do you know what is common in these products? Nobody answered, but he soon satisfied the general curiosity: their cost. Both products cost $\$ 17,000.00$ (seventeen thousand dollars).

This illustrates the high cost for accessing scholarly information by the scientific community. This information is the basic input to development of our research capacity. Who could obtain such publication? Which researcher or citizen could have access to it if there were no financial support by the Government?

Diário de Notícias, a newspaper from Portugal, published an article in its column Opinião written by the director-general of UNESCO, Koïchiro Matsuura, in which he comments the Unesco report Towards Knowledge Societies supporting the idea that social inequalities can only be reduced when common knowledge societies are built. However, there are barriers to reach these societies, and Koïchiro emphasizes two of them: cognitive exclusion and knowledge concentration.

Cognitive exclusion is stimulated by high costs of commercial scientific publication, and knowledge concentration results from the fact that great part of the current scientific knowledge has been produced by countries from the Northern Hemisphere. Therefore, researchers and directors of world organizations, such as the directorgeneral of UNESCO, are aware that reduction of social inequality depends on the open access to general and scientific information.

The open access movement is not only a response to the exorbitant increase of journals subscription prices. Its goals are higher than only providing open access to 
information; it aims at reducing the terrible social inequalities that affect all parts of the world by means of sharing scientific knowledge.

According to the UNESCO report mentioned above, approximately 2 billion people do not have access to electricity and three quarters of the world population has no or little access to telecommunication.

Brazil has joined this movement through the Brazilian Institute of Information on Science and Technology (IBICT), which has been one of the main interlocutors responsible for several initiatives towards the open access to scientific information. It is necessary to make clear that these actions do not compete with other initiatives such as CAPES Scientific Journals Portal.

CAPES Portal is strategically important for the Brazilian scientific development. It is therefore essential that this portal remain operating; that its utilization be extended; that the journals collection it offers the scientific and technological community be increased; and that public initiatives be conjugated in order to optimize the benefits of the relationship among the scientific community, the public sector, and the society.

It is important not only to strengthen CAPES Scientific Journals Portal, but also to follow the progress of the open access movement in several developed and developing countries. Involvement, assimilation and implementation of actions aimed at these purposes are IBICT's intrinsic roles.

Although $\underline{\mathrm{IBICT}}$ is supported by the Government and responsible for the technological and scientific information subsector, it should not centralize all the actions towards the open access movement. This effort must be shared with different segments of the scientific community.

Among these segments is the researchers community, one of the main pillars of this process since they produce Brazilian scientific literature. Funding agencies are coresponsible for this production because they encourage and support Brazilian research.

Institutions of higher learning and research are also important. As the hosts of research and researchers, they are responsible for creating open access repositories for the results of their work. These institutions, together with funding agencies, can define evaluation policies and criteria to encourage researchers to deposit their papers in open access repositories.

Another important segment of the scientific community is the scientific editors community. They are the guardians of the Brazilian scientific publication and 
responsible for defining criteria and business models for their journals in order to keep high quality and financial support. Today, the business model of our scientific publications is still very fragile and unsupportive.

Finally, IBICT plays the role of a facilitator and connector of institutions, services, processes and resources that favor the open access to scientific information.

Since the middle of 2001, IBICT has carried out studies and research based on the Open Archives model, which is the technological basis for the consolidation of the open access movement all over the world. Implementation of repositories and scientific publications has followed this model. Today, the Institute has technical competence to develop methodologies and technologies based on the Open Archives model.

An example of these initiatives is the Digital Library of Theses and Dissertations (BDTD) as well as the Electronic System for Journal Publishing (SEER). The number of scientific journals that use SEER is higher than one hundred. Because of this competence, IBICT could launch the portal Oasis.Br (Open Access Scholarly Information System), a service provider which collects metadata from all Brazilian journals that have information systems compatible with the Open Access model, including those indexed in SciELO. This portal is being planned and will soon present metadata from international electronic publications obtained from many portals such as the Directory of Open Access Journals (DOAJ).

Oasis. $\mathrm{Br}$ portal also collects metadata from institutional and thematic repositories such as Reposcom (of the communication area) or BDJur of the Superior Court of Justice (of the juridical area) or the Digital Library of Theses and Dissertations of IBICT.

The Brazilian Institute of Scientific and Technological Information has been publishing the goals of this movement as well as the technologies and methodologies for the production of repositories and electronic scientific publications, promoting and encouraging such actions, which have stimulated the creation of National Policies on Open Access to Scientific Information.

HÉLIO KURAMOTO, PhD in Information and Communication Sciences from Université Lumière, Lyon, France; General Coordinator of Special Projects of the Brazilian Institute of Scientific and Technological Information (IBICT), Email:kuramoto.ibict@gmail.com or kuramoto@ibict.br. 